\title{
CARACTERIZAÇÃO MORFOLÓGICA DE SEMENTES E PLÂNTULAS DE Koelreuteria paniculata Laxm.
}

\author{
Ramon Negrão Santos Junior ${ }^{1}$, Aderbal Gomes da Silva² \\ ${ }^{1}$ Engenheiro Florestal, Mestrando em Biologia Vegetal - Universidade Federal do \\ Espírito Santo, Vitória, Brasil. (ramonnegrao@outlook.com) \\ 2Professor Doutor da Universidade Federal de São João del-Rei, Sete Lagoas, \\ Brasil. \\ Recebido em: 08/04/2017 - Aprovado em: 10/06/2017 - Publicado em: 20/06/2017 \\ DOI: 10.18677/EnciBio_2017A28
}

\begin{abstract}
RESUMO
Koelreuteria paniculata, é uma espécie exótica de originária da Coréia, China e Japão. Este estudo objetivou descrever as características morfológicas do desenvolvimento de sementes e plântulas, ampliando 0 conhecimento das características de reconhecimento da espécie em seus estádios iniciais de vida. A germinação foi acompanhada desde o intumescimento da semente até a emissão dos protófilos de primeira ordem. Para a descrição da morfologia, os aspectos averiguados foram: comprimento, largura e espessura, além de características como dureza, coloração e formato das sementes. Após a observação das plântulas em laboratório, foram repicadas para tubetes de $180 \mathrm{~cm}^{3}$ preenchidos com o substrato vermiculita e levadas para viveiro, onde acompanhou-se o desenvolvimento das plântulas e posteriormente das plantas jovens. Semanalmente foram selecionadas 3 plântulas que representassem a amostra para a realização das medições, afim de se obter a representação do crescimento semanal. A germinação foi epígea e as plântulas formadas são fanerocotiledonares. Os aspectos morfológicos analisados são homogêneos e constantes, isto é, confiáveis, podendo auxiliar o reconhecimento da espécie nos estádios iniciais de vida.
\end{abstract}

PALAVRAS-CHAVE: Espécies ornamentais, morfologia, Sementes florestais.

\section{MORPHOLOGICAL CHARACTERIZATION OF SEEDS AND SEEDLINGS OF Koelreuteria paniculata Laxm.}

\begin{abstract}
Koelreuteria paniculata, is an exotic species originally from Korea, China and Japan. This study aimed to describe the morphological characteristics of the development of seeds and seedlings, expanding the knowledge of the caracteristics of recognition in their early stages of life. Germination was accompanied from the seed swelling to the issue of the first order protophilus. For the description of the morphology, the ascertained aspects were: length, width and thickness, besides characteristics such
\end{abstract}


as hardness, color and shape of the seeds. After the observation of the seedlings in the laboratory, they were pricking-out into $180 \mathrm{~cm}^{3}$ tubes filled with the vermiculite substrate and taken to nursery, where the development of the seedlings and later of the young plants. Weekly 3 seedlings have been selected to represent the sample for the measurements, in order to obtain the representation of the weekly growth. The germination was epigeal and the seedlings formed are phanerocotonares. The morphological aspects analyzed are homogeneous and constant, that is, reliable, and can help the recognition of the species in the early stages of life.

KEYWORDS: Forest seeds, Morphology, Ornamental species.

\section{INTRODUÇÃO}

Estudos sobre morfologia de sementes e plântulas são essenciais para fornecer dados e padrões que possibilitem o reconhecimento de uma espécie em campo nos estádios iniciais do seu desenvolvimento (OLIVEIRA et al., 2014), contribuindo para a estudos de regeneração natural (SANTOS-MOURA et al., 2016), auxiliando em estudos ecológicos e taxonômicos (KELLERMANN et al., 2016) e, além disso, possibilitando o melhor conhecimento de espécies exóticas potenciais para a ornamentação e arborização urbana. Desta forma, trabalhos sobre morfologia tem merecido atenção como parte de estudos morfoanatômicos, ampliando o conhecimento sobre determinada espécie ou grupamento sistemático de plantas, buscando o reconhecimento de sementes e plântulas (OLIVEIRA, 1993). Os estudos destes estádios iniciais de vida da planta são de grande relevância para a dinâmica populacional (LOPES \& DE SOUZA, 2015), além de propiciar informações importantes sobre o desenvolvimento da espécie, servindo como um subsídio para produção de mudas e permitindo uma melhor compreensão do processo de estabelecimento vegetativo (GUERRA et al., 2006).

O grau de confiabilidade das características morfológicas dependem da sua constância, quanto mais constantes forem as características encontradas mais confiáveis elas são (KONIYOSHI, 1983) contudo, pesquisas sobre morfologia de sementes e plântulas apontam a ocorrência de uma pequena capacidade fenotípica sendo de grande importância para a taxonomia, produzindo um conhecimento mais complexo a respeito das variações da espécie (TEICHMAN \& WYK, 1991), pois na natureza diversos fatores contribuem para o desenvolvimento diferenciado dos componentes da semente variando entre espécies e até mesmo dentro da própria espécie, através da cor, forma e tamanho (ABUD et al., 2009).

Koelreuteria paniculata Laxm (Sapindaceae), popularmente chamada de árvore chuva-de-ouro ou então de coreutéria é uma planta lenhosa nativa da China, Coréia e Japão. Possui folhas serrilhadas e inflorescências terminais com numerosas e vistosas flores de coloração amarelada, que em conjunto com seu tamanho e forma torna-a adequada para o paisagismo em geral, principalmente espaços gramados e jardins (REHMAN \& PARK, 2000). Sua madeira pode ser usada para confecção de móveis (WANG et al., 2013), porém no Brasil a possui a finalidade estritamente paisagística e ornamental (MARTINS et al., 2012; WANG et al., 2013).

Tendo em vista a escassez de estudos em caráter morfológico (LOUREIRO et al. 2013; OLIVEIRA et al., 2014; GOMES et al., 2015), sobretudo com os estádios iniciais de espécies ornamentais, que busquem expressar com maior particularidade sobre a descrição de sementes e plântulas, torna-se necessário suceder pesquisas ENCICLOPÉDIA BIOSFERA, Centro Científico Conhecer - Goiânia, v.14 n.25; p.300 2017 
para suprir e detalhar os períodos iniciais de desenvolvimento destas espécies. Sendo assim, este estudo objetivou descrever e elucidar as características morfológicas do desenvolvimento de sementes e plântulas de Koelreuteria paniculata, ampliando o conhecimento das características de reconhecimento da espécie em seus estádios iniciais de vida.

Nesta vertente, alguns estudos vêm sendo conduzidos para suprir estas informações, tais como DUARTE et al. (2015) que apresentaram dados sobre Albizia edwallii (Hoehne) Barneby \& J. W. Grimes, SILVA \& COSTA (2014), sobre Dalbergia nigra Vell., DE FREITAS et al. (2014) sobre Aspidosperma spruceanum BENTH., PINTO et al. (2016) sobre Oreopanax fulvus Marchal. e DE SOUZA et al. (2014), sobre Melanoxylon brauna e Kielmeyera lathrophyton, que podem seguramente ser empregadas para identificação taxonômica de sementes e plântulas destas espécies.

\section{MATERIAL E MÉTODOS}

As sementes de Koelreuteria paniculata foram coletadas em 10 matrizes na região de Sete Lagoas - MG e em seguida foram levadas para o laboratório de dendrologia e sementes florestais da Universidade Federal do Espírito Santo, no Departamento de Ciências Florestais e da Madeira sediado no município de Jerônimo Monteiro. As sementes foram beneficiadas, homogeneizadas para proporcionar a casualidade e armazenadas em câmara fria à $5^{\circ} \mathrm{C}$.

Para realizar a descrição da morfologia, foram selecionadas aleatoriamente 100 sementes e os aspectos averiguados foram: comprimento, largura e espessura, utilizando paquímetro digital, além de características como dureza, coloração e formato das sementes. O peso de mil sementes foi determinado de acordo com BRASIL (2009), sendo pesadas oito sub amostras contendo 100 sementes cada, em balança com precisão de $0.001 \mathrm{~g}$. Utilizando regra de três simples, foi calculado o número médio de sementes por quilo.

Os métodos e as terminologias utilizadas foram baseados em referências como OLIVEIRA (1993) e VIDAL \& VIDAL (2000). A caracterização morfológica das plântulas foi realizada descrevendo o processo de germinação das sementes, da manifestação da radícula até o aparecimento do epicótilo e protófilo. Nesta fase os caracteres fotografados e descritos foram: raiz (principal e secundária), coleto, hipocótilo, cotilédone, epicótilo e protófilos de primeira ordem. Para as medições das estruturas das plântulas foi utilizado paquímetro digital com precisão de 0,01 $\mathrm{mm}$.

Antes do início do experimento as sementes passaram por um processo de assepsia com hipoclorito de sódio a $10 \%$, sendo imersas na solução durante 3 minutos e posteriormente lavadas com água corrente por 2 minutos para retirar 0 excesso de cloro. A dormência tegumentar das sementes foi superada através da escarificação química (BRASIL, 2009), imergindo as sementes em solução de ácido sulfúrico $\left(\mathrm{H}_{2} \mathrm{SO}_{4}\right)$ por 5 minutos (SANTOS JÚNIOR \& SILVA, 2016) e lavando-as em água corrente por 2 minutos para retirar o excesso de ácido. Após este processo foram selecionadas ao acaso 100 sementes e separadas em 4 repetições de 25 sementes cada. As sementes foram dispostas em Gerbox entre papel Germitest e postas para germinar em Bioquimical Oxigen Demand - BOD, sob a temperatura de $25^{\circ} \mathrm{C}$ e luz constante.

A germinação foi acompanhada desde o intumescimento da semente até a emissão dos protófilos de primeira ordem. Foram consideradas estabelecidas as 
plântulas que apresentaram protófilos de primeira ordem totalmente expandidos. A seleção das plântulas para este estudo obedeceu ao critério de plântulas normais e anormais, onde plântulas normais são aquelas que apresentam todas as estruturas essenciais como: radícula, hipocótilo e/ou epicótilo e cotilédones.

Já as plântulas anormais foram consideradas como aquelas que apresentaram danos ou ausência de alguma das estruturas fundamentais (OLIVEIRA, 1993). Para obtenção de massa fresca (MF) as plântulas foram embaladas em sacolas de papel e pesadas em balança de precisão. Após este processo as plantas foram levadas a estufa de circulação forçada à $60^{\circ} \mathrm{C}$ por 24 horas e posteriormente retiradas e pesadas em balança de precisão, obtendo-se assim a massa seca (MS). Os valores em gramas de MF e MS foram obtidos através da média de todas as plântulas germinadas.

Após a observação das plântulas em laboratório, foram semeadas 100 sementes em condições semelhantes às descritas anteriormente e a partir da emissão da radícula foram repicadas para tubetes de $180 \mathrm{~cm}^{3}$ preenchidos com 0 substrato vermiculita e levadas para o viveiro do departamento, localizado em Jerônimo Monteiro, onde acompanhou-se o desenvolvimento das plântulas e posteriormente das plantas jovens. O acompanhamento se deu por 60 dias e a cada semana foram selecionados 3 indivíduos que representassem a amostra para a realização das medições do comprimento de raiz e parte aérea (PA), posteriormente sendo realizada a média destas variáveis afim de se obter a representação do crescimento semanal.

\section{RESULTADOS E DISCUSSÃO}

Características físicas e descrição morfológica das sementes de Koelreuteria paniculata.

A semente é de forma esférica e de coloração negra, com hilo amarronzado na parte superior da semente. Tem o tegumento espesso sendo necessária a escarificação antes da semeadura, possui testa lisa, dura, polida (Figura 1) e encontra-se presa em frutos do tipo cápsula, quando fixa a árvore.

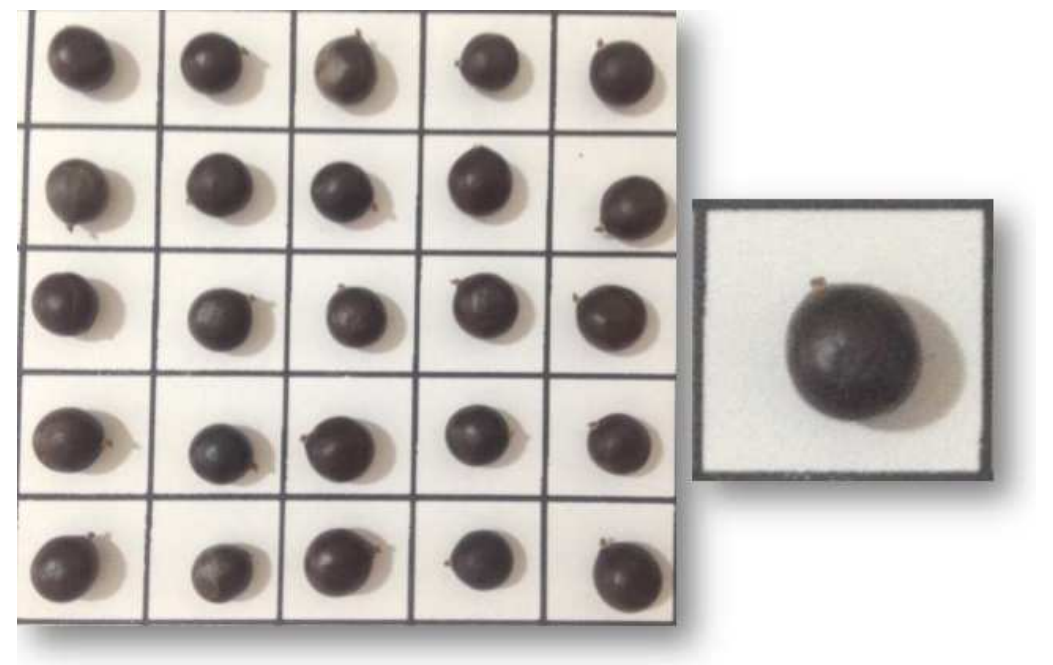

FIGURA 1. Aspectos morfológicos das sementes de Koelreuteria paniculata 
A semente apresenta comprimento médio de 5,26 $\mathrm{mm}$ (variando de 4,72 a $5,71 \mathrm{~mm}$ ) com o desvio padrão (DP) de $0,22 \mathrm{~mm}$ e coeficiente de variação (\%) - CV (\%) de 4,21, largura média de 4,62 $\mathrm{mm}$ (variando de 4,08 a 5,09 mm) com o DP de $0,21 \mathrm{~mm}$ e CV (\%) de 4,63 e espessura média de 3,98 $\mathrm{mm}$ (variando de 3,52 a 4,42 $\mathrm{mm}$ ) com o DP de $0,17 \mathrm{~mm}$ e CV (\%) de 4,31. O peso de 1000 sementes é de 56,14 gramas e o número de sementes por quilo é de 17.811,66 conforme apresentado na Tabela 1.

TABELA 1. Características físicas das sementes de Koelreuteria paniculata.

\begin{tabular}{ccccccc}
\hline Dimensões & Mínimo & Média & Máximo & Amplitude & DP & CV (\%) \\
\hline Comprimento $(\mathrm{mm})$ & 4,72 & 5,26 & 5,71 & 0,99 & $\pm 0,22$ & 4,21 \\
Largura $(\mathrm{mm})$ & 4,08 & 4,62 & 5,09 & 1,01 & $\pm 0,21$ & 4,63 \\
Espessura $(\mathrm{mm})$ & 3,52 & 3,98 & 4,42 & 0,90 & $\pm 0,17$ & 4,31 \\
\hline \multicolumn{7}{c}{56,14} \\
\hline Peso de 1000 sementes (g) & \multicolumn{7}{c}{$17.811,66$} \\
Número de sementes por Kg
\end{tabular}

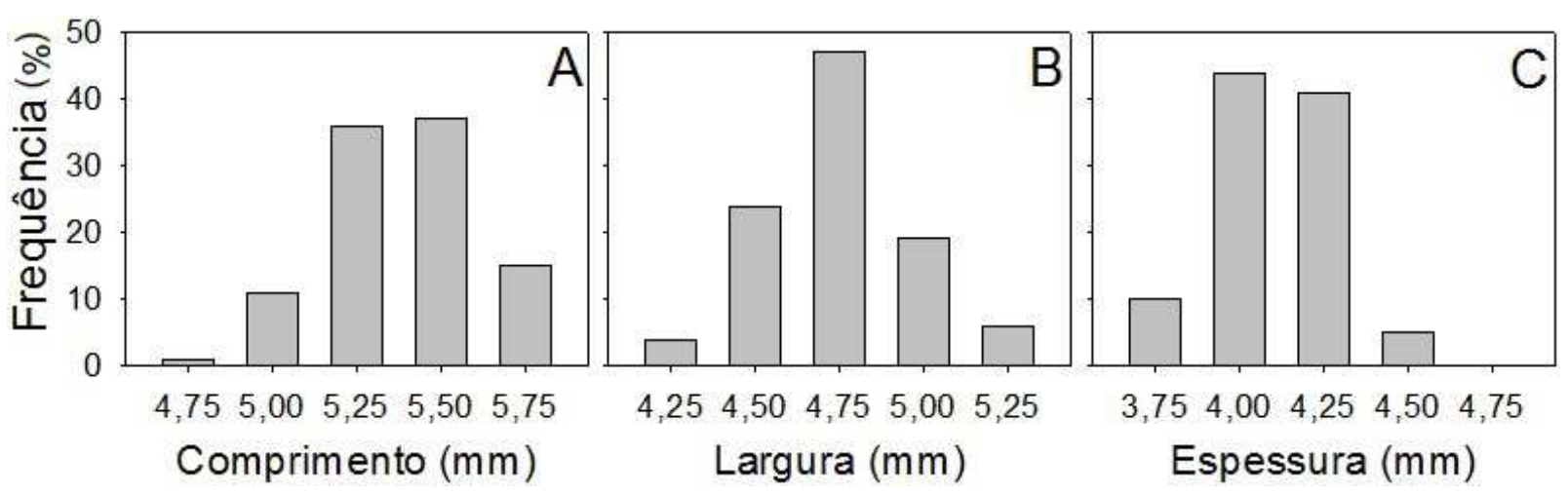

FIGURA 2 - Distribuição de frequência em porcentagem do comprimento, largura e espessura de sementes de Koelreuteria paniculata.

Descrição morfológica das plântulas de Koelreuteria paniculata

A germinação é epígea e teve início entre 5 a 7 dias do momento da semeadura (Figura 3B). A plântula formada é fanerocotiledonar, ou seja, seus cotilédones se desprendem da semente após o processo de germinação. Estes cotilédones são de coloração verde-clara, simétricos, opostos, carnosos, livres e oblongos com ápice arredondados. As raízes, tanto a principal quanto as secundárias são de coloração esbranquiçada.

Após a emissão da radícula que é fina, cônica e esbranquiçada (Figura $3 C$ ), há um alongamento da mesma onde passa a se diferenciar do hipocótilo, que apresenta coloração avermelhada, formato cilíndrico, levemente flexível, ligeiramente ondulado, liso e glabro (Figura 3D; 3E). A zona de transição entre a raiz 
e o hipocótilo é denominada de coleto. O coleto é evidenciado pela diferença de coloração entre a raiz (esbranquiçada) e o hipocótilo (avermelhado). Conforme o hipocótilo vai crescendo os cotilédones se desprendem do topo dessa estrutura (Figura 3F), permitindo observar estruturas como o epicótilo, gema apical e folíolo (Figura 3G).

A Figura 2 ilustra a sequência das fases de crescimento das fases vegetativas citadas acima. As plântulas obtiveram os valores de $1.96 \mathrm{~g}$ e $0.017 \mathrm{~g}$ para MF e MS, respectivamente, e a porcentagem de plântulas normais foi de $29 \%$.

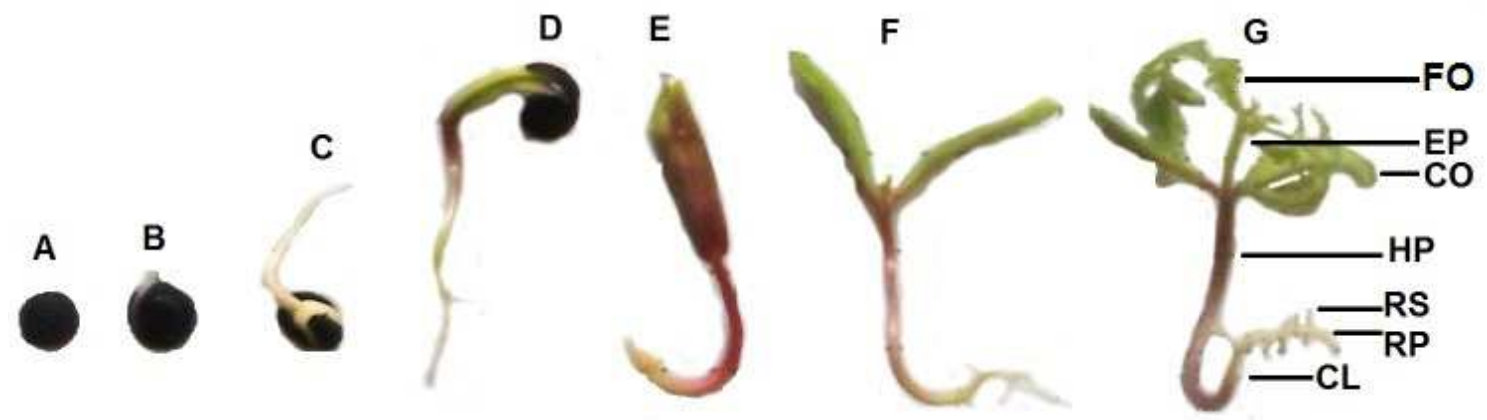

FIGURA 3. Fases do desenvolvimento germinativo de Koelreuteria paniculata. A: Semente de Koelreuteria paniculata, B: Início da germinação Rompimento do tegumento, C: Alongamento da radícula, D: Diferenciação da radícula, coleto e hipocótilo, E: Desprendimento dos cotilédones da casca para dar início ao processo de abertura, $F$ : Abertura dos cotilédones e aparecimento da gema apical, G: Surgimento do epicótilo e abertura total do primeiro par de folhas. Legenda: $\mathbf{R p}$ - Raiz primária, Rs - Raiz secundária, $\mathbf{C l}$ - Coleto, $\mathbf{H p}-$ Hipocótilo, Ep - Epicótilo, Co - Cotilédone, Fo - Folíolo.

As sementes de Koelreuteria paniculata são pequenas quando comparadas as de outras Sapindaceae, como Allophylus edulis e Talisia esculenta estudadas por ABREU et al. (2005) e VIEIRA \& GUSMÃO (2008) respectivamente. Além disso essas espécies obtiveram o coeficiente de variação (CV) de 7 a $8 \%$ para a primeira e 4 a $6 \%$ para a segunda, enquanto que a K.paniculata apresentou CV em torno de $4 \%$, insinuando que esta possui características mais homogêneas, isto é, menos variáveis em relação as espécies comparadas. Além disso, o tamanho reduzido das sementes confere um baixo peso para 1000 sementes e um elevado número de sementes por quilo. Quanto ao aspecto, sementes de K.paniculata apresentam características de formato, textura, coloração e dureza semelhantes as outras espécies do gênero como Koelreuteria bipinata e Koelreuteria elegans (MEYER, 1976). Entretanto peculiaridades como sementes esféricas, lisas e duras também podem ser encontradas em outros membros das Sapindaceae (PAOLI \& BIANCONI, 2008).

ABREU et al. (2005) estudando morfologia e germinação de A.edulis observaram que a germinação é epígea e a formação da plântula fanerocotiledonar, assim como observado em K.paniculata, contudo verificou-se em outros membros da família Sapindaceae germinação do tipo hipógea e plântula criptocotiledonar, isto é, quando os cotilédones não se despendem do tegumento como a Pseudima 
frutescens (PAOLI \& BIANCONI, 2008) e Sapindus saponária (PAOLI \& SANTOS, 1998). Isso se dá em decorrência das Sapindaceae constituírem uma família cosmopolita que contém desde árvores e arbusto até lianas e ervas encontradas nos mais diferentes ecossistemas tropicais e subtropicais (SOMMER, 2009). Dentro das Sapindaceae é comum a presença de espécies que apresentem tanto cotilédones carnosos como T.esculenta (VIEIRA \& GUSMÃO, 2008) e P.frutescens (PAOLI \& BIANCONI, 2008), quanto cotilédones foliáceos como A.edulis (ABREU et al., 2005). Contudo, interessantemente, contrastando com o encontrado nesse estudo os cotilédones de K.paniculata descritos por MEYER (1976) são foliáceos. Levantando indícios de plasticidade fenotípica dentro da espécie para responder as variações do ambiente (LOFEU \& KOHLSDORF, 2015). MEYER (1976), também observou que o primeiro par de folhas verdadeiras é pinado, raramente bipinado, e fortemente serrilhado durante os estádios iniciais de vida da planta. Essas características tornam a K.paniculata facilmente distinguível das demais espécies do gênero.

Semeadura em viveiro e acompanhamento das plântulas e plantas jovens por 60 dias

Ao final do período de observação das plântulas em viveiro, pôde-se constatar a presença de dois pares de folhas compostas, pinadas, imparipenadas, apresentando de 4 a 5 pares de folíolos, opostos, com nervura peninérvea, bordas serrilhadas, pilosidade na face abaxial e consistência herbácea, como pode ser observado na Figura 4.

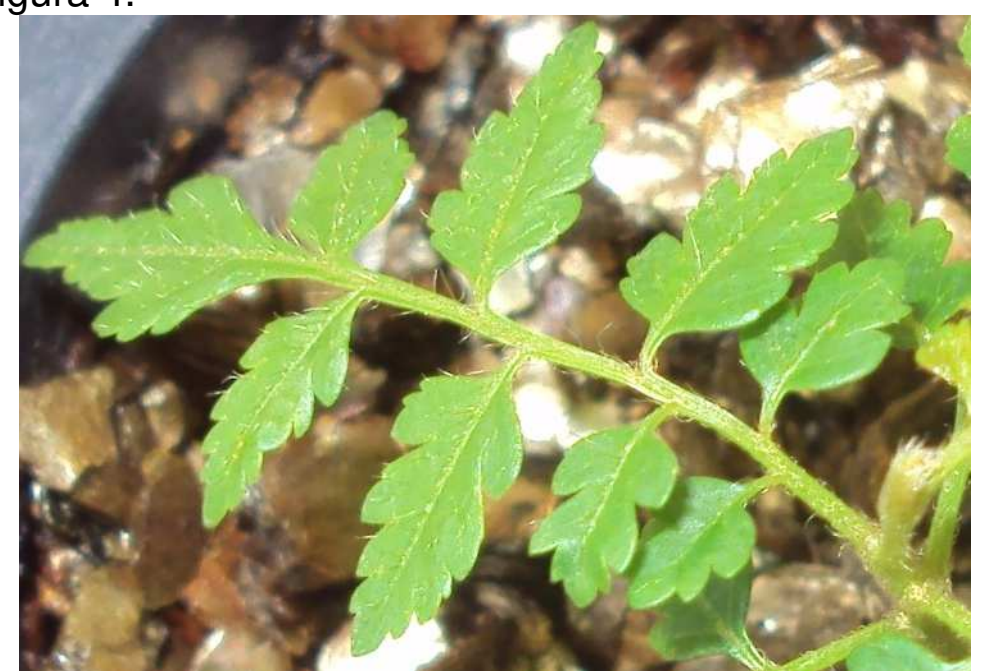

FIGURA 4. Folha de Koelreuteria panicula aos 60 dias.

A Figura 5 representa os dados de raiz e PA coletados semanalmente entre os meses de Junho e Julho. Nos dias 06 e 13 (3 e 10 dias após a germinação, respectivamente.) de Junho não houve coleta das plântulas para medição, pois a PA ainda não estava formada. A partir das demais semanas as medições ocorreram normalmente. Ao final da $8^{\mathrm{a}}$ semana a plântula atingiu as médias de $15.7 \mathrm{~cm}$ para raiz e $3.16 \mathrm{~cm}$ para $\mathrm{PA}$. 


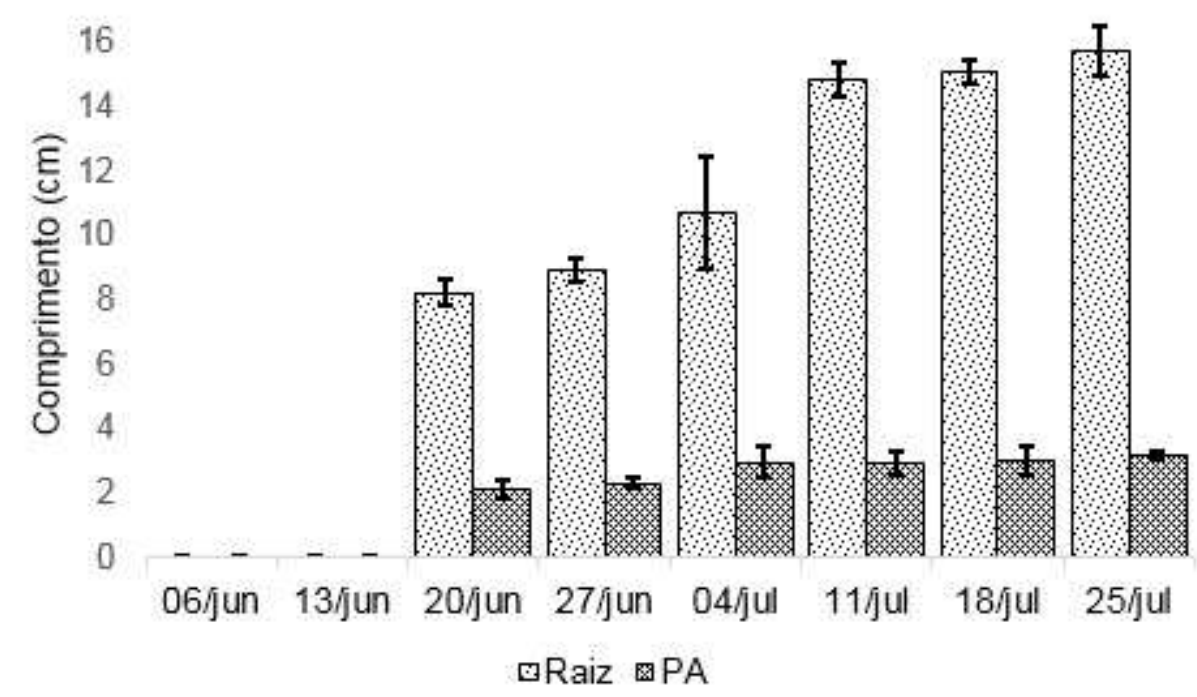

FIGURA 5. Medições semanais do comprimento de raiz e parte aérea das mudas de K.paniculata. Os valores correspondem as médias de cada medição \pm 0 desvio padrão $(\mathrm{n}=3)$.

Pode-se perceber que há diferença entre os valores absolutos da primeira e a última medição são bem maiores em relação a raiz que obteve na primeira medição a média de $8,2 \mathrm{~cm}$ (variando entre 7,8 e 8,6 cm) e na última $15,7 \mathrm{~cm}$ (variando entre $15,1 \mathrm{~cm}$ e $16,6 \mathrm{~cm}$ ) comparado ao crescimento da PA que obteve 2,1 cm (variando entre 1,8 e 2,4 cm) na primeira medição e $3,16 \mathrm{~cm}$ na última (variando entre 2,8 e $3,3 \mathrm{~cm}$ ). Logo, enquanto a raiz cresceu $91,5 \%$ durante as 8 semanas a PA cresceu apenas $50,5 \%$ no mesmo período.

É provável que a raiz tenha sido estimulada pela vermiculita, já que em outros trabalhos este fato já foi observado, como por exemplo, em LIMA et al., (2016). Já DA SILVA et al. (2013), estudando mudas de Tamarindus indica L., perceberam que a adição de vermiculita ao substrato comercial propiciou mudas de melhor qualidade, enquanto DIAS et al. (2015) além de bons resultados com enraizamento também obtiveram acréscimo em altura, diâmetro do coleto e peso de MS. Em contrapartida DA SILVA et al., (2012), estudando o enraizamento em mudas de Eucaliptus $s p$. verificaram que os substratos com maior proporção de vermiculita produziram mudas com menos massa seca de PA.

\section{CONCLUSÕES}

As sementes de Koelreuteria paniculata são esféricas, lisas, duras, polidas e negras. Apresentaram germinação epígea com início entre cinco a sete dias após a semeadura e as plântulas formadas são fanerocotiledonares.

Os aspectos morfológicos analisados são homogêneos e constantes, isto é, confiáveis, podendo auxiliar o reconhecimento da espécie seja em lotes de sementes ou nos estádios iniciais de vida.

As margens foliares são fortemente serrilhadas, esse atributo contribui para identificação da espécie. 


\section{REFERÊNCIAS}

ABREU, D. C. A., KUNIYOSHI, Y. S., NOGUEIRA, A. C., MEDEIROS, A. C. S. Caracterização Morfológica de Frutos, sementes e germinação de Allophylus edulis (ST.-HIL.) RADLK. (SAPINDACEAE), Revista Brasileira de Sementes, v. 27, n. 2, p.59-66, 2005. Disponível em: http://dx.doi.org/10.1590/S0101-31222005000200009, Acesso em: 07 Mai 2017.

ABUD, H. F.; REIS, R. G. E.; TEÓFILO, E. M. Caracterização morfológica de frutos, sementes, plântulas e germinação de Mucuna aterrima Piper \& Tracy. Revista Ciência Agronômica, v. 40, n. 4, p. 563-569, 2009. Disponível em: http://www.ccarevista.ufc.br/seer/index.php/ccarevista/article/view/893/383, Acesso em: 02 Fev 2017.

BRASIL. Ministério da Agricultura e Reforma Agrária. Secretaria Nacional de Defesa Agropecuária. Departamento Nacional de Defesa Vegetal. Coordenação de Laboratório Vegetal. Regras para análise de sementes. Brasília, DF, 2009. 399p.

DA SILVA, C. A.; DE ALMEIDA, M. S.; DE MELO, B. e DA SILVA, C. J. Mudas de tamarindeiro em função de tamanhos de recipiente e doses de vermiculita. Acta Tecnológica, v.8, n.1, p. 5-11, 2013. Disponível em: http://portaldeperiodicos.ifma.edu.br/index.php/actatecnologica/article/viewFile/89/11 7, Acesso em: 02 Fev 2017.

DA SILVA, R. B. G.; SIMÕES, D.; DA SILVA, M. R. Qualidade de mudas clonais de Eucalyptus urophylla x E. grandis em função do substrato. Revista Brasileira de Engenharia Agrícola e Ambiental. João Pessoa, v. 16, n. 3, p. 297-302, 2012. Disponível em: http://dx.doi.org/10.1590/S1415-43662012000300010, Acesso em: 02 Fev 2017.

DE FREITAS, A. D. D.; LEÃO, N. V. M.; DE POTIGUARA, R. C. V.; REIS, A. R. S. e SOUSA, D. V. Caracterização Morfológica do Fruto, Semente e Desenvolvimento Pós-Seminal de Aspidosperma spruceanum BENTH. EX MULL. ARG. (APOCYNACEAE). Enciclopédia Biosfera, Centro Científico Conhecer - Goiânia, v. 10, n.18, 2014. Disponível em: http://www.conhecer.org.br/enciclop/2014a/AGRARIAS/caracterizacao\%20morfologi ca\%20do.pdf, Acesso em 02 Fev 2017.

DE SOUZA, P. F., NERY, M. C.; PIRES, R. M. O.; PINTO, N. A. V. D. e SOARES, B. C. Caracterização Morfológica e Composição Química de Sementes de Espécies Florestais. Enciclopédia Biosfera, Centro Científico Conhecer - Goiânia, v. 10, n.18, 2014.2 Disponível em: http://www.conhecer.org.br/enciclop/2014a/AGRARIAS/caracterizacao\%20morfologi ca\%20e.pdf, Acesso em 02 Fev 2017.

DIAS, P. C; XAVIER, A.; DE OLIVEIRA, L. S.; CORREIA, A. C. G. e BARBOSA, G. A. Tipo de miniestaca e de substrato na propagação vegetativa de Angico-vermelho (Anadenanthera macrocarpa (Benth.) Brenan. Ciência Florestal, Santa Maria, v. 25, n. 4, p. 909-919, 2015. Disponível em: http://dx.doi.org/10.5902/1980509820593, Acesso em 02 Fev 2017. 
DUARTE, M. M., MILANI, J. E. DE F., BLUM, C. T., NOGUEIRA, A. C. Germinação e Morfologia de sementes e plântulas de Albizia edwallii (Hoenhe) Barneby \& J. W. Grimes. Revista Caatinga, Mossoró, v. 28, n.3, p. 166 - 173, jul. - set, 2015. Disponível em: http://dx.doi.org/10.1590/1983-21252015v28n319rc, Acesso em 02 Fev 2017.

GOMES, J. P.; DE OLIVEIRA, L . M.; FRANÇA, C. S. S.; DACOREGIO, H. M. e BORTOLUZZI, R. L. C. Caracterização de Plântulas Durante a Germinação de Sementes de Psidium cattleianum e Acca sellowiana (Myrtaceae). Ciência Florestal, Santa Maria, v.25, n.4, 2015. Disponível em: http://dx.doi.org/10.5902/19805098, Acesso em 15 Fev 2017

GUERRA, M. E. C.; MEDEIROS FILHO, S.; GALLÃO, M.I. Morfologia de sementes, de plântulas e da germinação de Copaifera langsdorfii Desf. (Leguminosae Caesalpinioideae). Revista Cerne, Lavras, v.12, n.4, 2006. Disponível em: http://www.redalyc.org/articulo.oa?id=74412403, Acesso em 02 Fev 2017.

KELLERMANN, B., BONA, C., DE SOUZA, L. A. Morfoanatomia da plântula e comparação da folha nas fases juvenis e adulta de Piptocarpha angustifolia (Asteraceae). Rodriguésia, v. 67, n. 3, Rio de Janeiro July/Sept. 2016. Disponível em: http://dx.doi.org/10.1590/2175-7860201667307, Acesso em: 16 Mar 2017

KUNIYOSHI, Y.S. Morfologia da semente e da germinação de 25 espécies arbóreas de uma floresta com Araucaria. 1983. 233f. Dissertação (Mestrado em Engenharia Florestal) - Universidade Federal do Paraná, Curitiba, 1983. Disponível em: http://acervodigital.ufpr.br/bitstream/handle/1884/25193/D\%20\%20KUNIYOSHI,\%20YOSHIKO\%20SAITO.pdf\%3Bjsessionid=3C3EAC\%2080F4D2 210210D17E848171A318?sequence=1, Acesso em: 02 Fev 2017

LIMA, C. C.; OHASHI, S. T. Substrato no Enraizamento de Estacas Provenientes de Mudas de Schizolobium parahyba var. amazonicum. Enciclopédia Biosfera, Centro Científico Conhecer - Goiânia, v.13, n.23, p.1270, 2016. Disponível em: DOI: 10.18677/Enciclopedia_Biosfera_2016_112, Acesso em 16 Mar 2017.

LOFEU, L., KOHLSDORF, T. Mais que seleção: o papel do ambiente na origem da evolução da diversidade fenotípica. Genética na Escola, v. 10, n. 1, p. 11-19, 2015. Disponível em: www.researchgate.net/publication/295968268, Acesso em: 07 Mai 2017.

LOPES, W. A. L. e DE SOUZA, L . A. Morphoanatomy of Serjania communis Cambess. Seedling (Sapidaceae). Acta Scientiarum, v.37, n.3, 2015. Disponível em: http://periodicos.uem.br/ojs/index.php/ActaSciBiolSci/article/view/27484, Acesso em: 02 Fev 2017

LOUREIRO, M. B.; TEleS, C. A. S.; COlARES, C. C. A.; DE ARAÚJO, B. R. N.; FERNANDEZ, L. G. e CASTRO, R. D. Caracterização Morfoanatomica e Fisiológica de Sementes e Plântulas de Jatropha curcas L. (Euphorbiaceae). Revista Árvore, 
v.37, n.6, 2013. Disponível em: http://dx.doi.org/10.1590/S010067622013000600011, Acesso em: 02 Fev 2017

MARTINS, C. H. Z.; FREIRE, M. G. M.; PARRA, J. R. P. and MACEDO, M. R. L. Physiological and Biochiemical Effects of an Aqueous Extract of Koelreuteria paniculata (Laxm.) Seeds on Anticarsia gemmatalis (Huebner) (Lepidoptera: Noctuidae. SOAJ Entomological, v. 1, p.49-61, 2012. Disponível em: https://www.researchgate.net/publication/237022527_PHYSIOLOGICAL_AND_BIOC HEMICAL_EFFECTS_OF_AN_AQUEOUS_EXTRACT_OF_Koelreuteria_paniculata Laxm_SEEDDS_ON_Anticarsia_gemmatalis_Huebner_LEPIDOPTERA_NOCTUIDAE, Acesso em: 02 Fev 2017.

MEYER, F. G. A Revision of the genus koelreuteria (SAPINDACEAE). Journal of the Arnold Arboretum, Cambridge, Mass. :Arnold Arboretum, Harvard University Disponível em: http://www.biodiversitylibrary.org/item/41448, Acesso em: 07 Mai 2017.

OLIVEIRA, E. C. Germinação de sementes. In: Aguiar, I.B.; Piña-Rodrigues, F. C. M., Figliolia, M.B. (coord). Sementes florestais tropicais. Brasília: ABRANTES, 1993. 175-214p.

OLIVEIRA, J. H. G., IWAZAKI, M. C., OLIVEIRA, D. M. T. Morfologia das plântulas, anatomia e venação dos cotilédones e eofilos de três espécies de Mimosa (Fabaceae, Mimosideae). Rodriguésia 65(3): 777-789. 2014. Disponível em: http://dx.doi.org/10.1590/2175-7860201465315, Acesso em: 02 Fev 2017.

PAOLI, A. A. S., BIANCONI, A.; Caracterização Morfológica de Frutos, sementes e plântulas de Pseudima frutescens (Aubl.) Radlk. (SAPINDACEAE), Revista Brasileira de Sementes, v. 30, n.2, p.146-155, 2008. Disponível em: DOI: 10.1590/S0101-31222008000200018, Acesso em: 07 Mai 2017.

PAOLI, A. S., SANTOS, M. R. O.; Caracterização Morfológica de Frutos, sementes e plântulas de Sapindus saponaria L. (SAPINDACEAE). Revista Brasileira de Sementes, vol. 20, no 2, p.147-153 - 1998. Disponível em: www.researchgate.net/publication/242122204, Acesso em: 07 Mai 2017.

PIMENTEL, N; BISOGNIN, D. A.; KIELSE, P. LENCINA, K. H. e MELLO, U. S. Shoot segment and substrate composition in rooting of juvenile ipe-roxo mini-cuttings. Ciência Rural, Santa Maria, v. 46, n. 6, p. 996-1002, June, 2016. Disponível em: http://dx.doi.org/10.1590/0103-8478cr20140361, Acesso em: 02 Fev 2017

PINTO, M. B., GRABIAS, J., hOFFMANN, P. M., VELAZCO, S. J. E., BLUM, C. T. Caracterização morfológica de frutos, sementes e plântulas e germinação de Oreopanax fluvus Marchal. Revista Brasileira de Ciências Agrárias, Recife, v. 11, n. 2, p. 111-116, 2016. Disponível em: http://dx.doi.org/ 10.5039/agraria.v11i2a5366, Acesso em: 02 Fev 20177.

SANTOS JÚNIOR, R. N. e SILVA, A. G.; Superação de Dormência em Sementes de Koelreuteria paniculata LAXM. Enciclopédia Biosfera, Centro Científico Conhecer - 
Goiânia, v. 13, n.33, 2016. Disponível em: DOI: 10.18677/Enciclopedia_Biosfera_2016_113, Acesso em 02 Fev 2017.

SANTOS-MOURA, S. S., GONÇALVES, E. P., MELO, F. D. L. A., PAIVA, L. G., SILVA, T. M.; Morphology of fruits, diaspores, seeds, seedlings, and saplings of Syagrus coronata (Mart.) Becc. Bioscience Journal, Uberlândia, v. 32, n. 3, p. 652660, May/June. 2016. Disponível em: DOI: http://dx.doi.org/10.14393/BJv32n3a2016-32829, Acesso em 16 Mar 2017.

SILVA, A. G. e COSTA, L. G. Germinação, Morfologia de Frutos, Sementes e Plântulas de Jacarandá-da-Bahia (Dalbergia nigra (Vell.) Fr. All. ex. Benth.) Enciclopédia Biosfera, Centro Científico Conhecer - Goiânia, v.10, n.18, 2014. Disponível em: http://www.conhecer.org.br/enciclop/2014a/AGRARIAS/Germinacao\%20morfologia.p df, Acesso em 02 Fev 2017.

SOMMER, G. V. (Coord.). Sapindaceae In: Martins, S.E., Wanderley, M.G.L., Shepherd, G.J., Giulietti, A.M., Melhem, T.S. (eds.) Flora Fanerogâmica do Estado de São Paulo. Instituto de Botânica, São Paulo, v. 6, p. 195-256, 2009. Disponível em: http://botanica.sp.gov.br/ffesp_online/, Acesso em: 07 Mai 2017.

VIDAL, W. N.; VIDAL, M. R. R. Botânica: organografia. 4. ed. Viçosa: UFV, 2000, $114 p$.

VIEIRA, F. A., GUSMÃO E.; Biometria, armazenamento de semntes e emergência de plântulas de Talisia esculenta Radlk. (Sapindaceae), Ciência e Agrotecnologia, Lavras, v. 32, n. 4, p. 1073-1079, jul./ago., 2008. Disponível em: https://www.researchgate.net/publication/237211361, Acesso em: 07 Mai 2017.

VON TEICHMAN, I.; VAN WYK, A.E. Trends in the evolution of dicotyledonous seeds based on character associations, with special reference to pachychalazy and recalcitrance. Botanical Journal of the Linnean Society, v. 105, n. 3, p. 211-237, 1991. Disponível em: DOI: 10.1111/j.1095-8339.1991.tb00205.x, Acesso em 02 Fev 2017.

WANG, Q.; MANCHESTER, S. R.; GREGOR, H. J.; SHEN, S. and LI, Z. Y. Fruits os Koelreuteria (Sapidaceae) From the Cenozoic Throughout the Northern Hemisphere: Their Ecological, Evolutionary, and Biogeographic Implications. American Journal of Botany. v.100, n.2, p.422-449, 2013. Disponível em: http://www.amjbot.org/content/100/2/422.short, Acesso em: 02 Fev 2017. 